\title{
Advances of Nanotechnology Applied to Biosensors
}

Chen Gui, Xuan Dai, Daxiang Cui*

Department of Bio-Nano Science and Engineering, Key Laboratory for Thin Film and Microfabrication Technology of Ministry of Education, National Key Laboratory of Micro /Nano Fabrication Technology, Research Institute of Micro/Nano Science and Technology, Shanghai Jiao Tong University, Shanghai, 200240, P.R. China

*Corresponding authors: dxcui@sjtu.edu.cn; (Daxiang Cui) Tel.: +86-21-34206375; Fax: +86-21-34206886

\begin{abstract}
Up to date, application of nanomaterials and nanotechnology has made great advances. Many novel nanomaterials with unique properties are increasingly being exploited to apply for biosensors, improving the property of biosensor and making them higher selectivity and sensitivity, less response time and lower detective limitation. Here we review some of the main advances in this field over the past few years, explore the application prospects, and discuss the issues, approaches, and challenges, with the amin of promting to develop nanomaterials-based biosensor nanotechnology and improving their application in disease diagnosis and biosafety examination.
\end{abstract}

Keywords: biosensor; nanotechnology; gold nanoparticle; carbon nnaotubes; magnetic nanoparticles

Citation: C. Gui, et al. Advances of Nanotechnology Applied to Biosensors. Nano Biomed. Eng. 2011, 3(4), 260-273. DOI: 10.5101/nbe.v3i4. p260-273

\section{Introduction}

Nanobiotechnology is defined as an interdisciplinary field of science that studies the application of fine-sized biological objects (of nanoscale, 1-100 nm) to design the devices and systems of the same size that utilize their unique effects for new purposes [1]. As the development of nanotechnology, the nanotechnology has been applied to biosensors such as nanoelectrodes and nanoelectrode arrays to improve their performance. Nanobiosensor, an integration of physical sciences, molecular engineering, biology, chemistry and biotechnology holds the possibility of detecting and manipulating atoms and molecules using nanodevices, which have the potential for a wide range of both industrial and domestic applications [2].

Herein, we review some of current main advances of nanotechnology applied to biosensors. Firstly, we give some examples of different nanomaterials such as gold nanoparticles, carbon nnaotubes(CNTs) and magnetic nanoparticles used in biosensors as electrode or membranes to enhance the biomolecule absorption or immobilization. Then we summary main types of biosensors such as electrochemical bosensors, immune biosensors, and giant magnetic resitance (GMR)- sensors. Lastly, we explore the application prospects, and discuss the issues, approaches, and challenges, with the amin of promting to develop nanomaterials-based biosensor nanotechnology and improving their application in disease diagnosis and biosafety examination.

\section{The use of nanomaterials in biosensor}

Nanomaterials such as gold nanoparticles, carbon nanotubes (CNTs), magnetic nanoparticles, etc. own great potential applications in biosensors owing to their unique properties [3-5]. In recent years, the application of these nanomaterials in biosensors have achieved great advances.

\subsection{The use of gold nanoparticle in biosensor}

The presence of gold nanoparticle in biosensor, provides a biocompatible microenvironment for biomolecules, greatly amplified the immobilized amount of biomolecules on the electrode surface, and improved the sensitivity of the biosensors [6-8]. And different structure of gold nanoparticle showed different property. The gold nanorods modified electrode layer showed better analytical response than gold nano particles [9].Bikash Kumar Jena et al [10].demonstrated the bioanalytical application of gold nanoparticles for the sensing of polyionic drugs, protamine and heparin by reversible aggregation/de-aggregation for the first time. 
Non-crosslinking gold nanoparticle aggregation induced by the loss (or screen) of surface charges is applied for enzymatic activity sensing and potentially inhibitor screening [11]. Hui Wei et al [12]. described simple and sensitive aptamer-based colorimetric sensing of protein (alpha-thrombin in this work) using unmodified gold nanoparticle probes as shown in Fig. 1.

Glassy carbon electrode (GCE) was widely used in biosensor; modified GCE could adsorb gold nanoparticle to improve the activity of the biosensors [13]. Gold nanoparticle and methylene blue (MB) could be assembled layer-by-layer (LBL) into films on the GCE modified by thiourea for detection of human chorionic gonadotrophin (HCG) [14].Due to the high surface area of the nanoparticles for loading anti-HCG, the immunosensor would be a potential application on clinical determination of HCG level. And gold nanoparticlemodified electrode showed much wider $\mathrm{pH}$ adaptive range, much better electrochemical stability and larger response current to the reduction of $\mathrm{H}_{2} \mathrm{O}_{2}$ [15]. Ai Wu Shi et al [16]. demonstrated a simple and low-cost way for the fabrication of amperometric $\mathrm{H}_{2} \mathrm{O}_{2}$ biosensors based on in situ electropolymerization of PTHNWs-HRP-gold nanoparticle with the help of the AAO template.

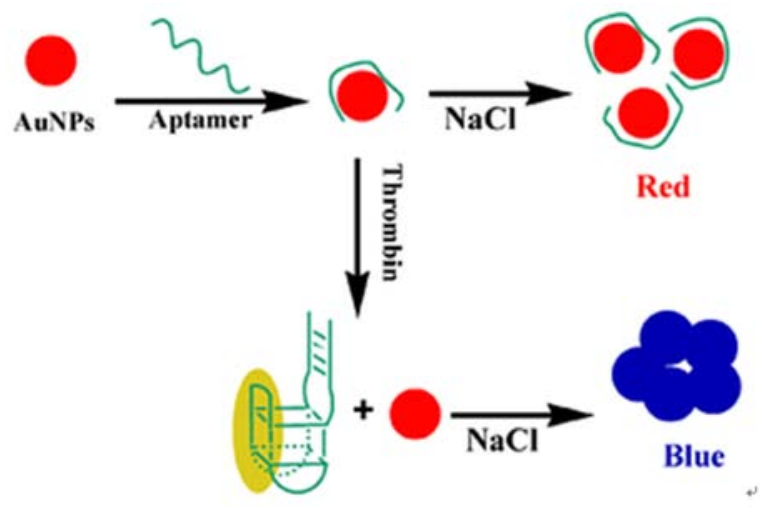

Fig. 1 AuNPs colorimetric strategy for thrombin detection[12].

Adoped with gold nanoparticle could improve the detection skill of bisosensor. For the first time, those GNPs/CNTs nanohybrids were used to construct an electrochemical immunosensor for highly sensitive immunoassay [17]. This developed label method was versatile, offers enhanced performances, and could be easily extended to other protein detection schemes as well as in DNA analysis. A nano-composite $\mathrm{ZrO}_{2} / \mathrm{Au}$ film was prepared through a combination of sol-gel procedure and electroless plating that can be carried out in a general chemistry lab with no need for special facilities and reagents [18]. The specific strong adsorption of OPs on the homemade $\mathrm{ZrO}_{2} / \mathrm{Au}$ film electrode surface provides an effective quantitative method for OP pesticides analysis.

\subsection{The use of CNT in biosensor}

Electrostatic interactions between a cationic surfactant/ polymer and CNTs were utilized for the fabrication of biosensors [19]. Jinxiang Zeng et al [20]. described a way for fabrication of Prussian Blue nanoparticles/carbon nanotubes/poly (1,2-diaminobenzene) based glucose biosensor. The selectivity was greatly improved due to lower operation potential afford by the catalytic ability of PB/MWNTs nanocomposite toward reduction of hydrogen peroxide and the excellent anti-interference ability of PDAB film. An organic plasma polymer coating method [21]. provided a well-defined nanocomposite of enzyme, CNTs, and PPFs, the resulting device showed that the oxidizing current response due to enzymatic reaction was 4-16-fold larger than that with only CNT or PPF. Compared with the biosensor without carbon nanotube modification, the CNTs improved the sensitivity of the biosensor up to five times [22]. Hitoshi Muguruma et al [23]. reported an amperometric biosensor that is based on a nanocomposite of CNT, PPF, and GOx as an enzyme model. A mixture of the GOx and a CNT film is sandwiched with 10-nm-thick acetonitrile PPFs.

The bionanocomposite layer of multiwalled carbon nanotubes (MWNT) in chitosan (CHIT) can be used in the detection of DNA [24]. The biocomponent represented by double-stranded herring sperm DNA was immobilized on this composite using layer-by-layer coverage to form a robust film [25]. SsDNA probes could be immobilized on the surface of GCE modified with MWNTs/ZnO/CHIT composite film. The sensor can effectively discriminate different DNA sequences related to PAT gene in the transgenic corn, with a detection limit of $2.8 \mathrm{~mol} \mathrm{~L}^{-1}$ of target sequence.

Carbon nanofibers are found to be an effective strategy for building a biosensor platform [26]. Hui Ping Bai et al [27]. found that the synergistic effects of MWNTs and $\mathrm{ZnO}$ improved the performance of the biosensor. They reported an amperometric biosensor for hydrogen peroxide, which was developed based on adsorption of horseradish peroxidase at the GCE modified with $\mathrm{ZnO}$ nanoflowers produced by electrodeposition onto MWNTs film. Shu Ping Zhang et al [28]. described a controllable layer-by-layer self-assembly modification technique of GCE with MWNTs [29,30]. and introduce a controllable direct immobilization of acetylcholinesterase (AChE) on the modified electrode. By the activity decreasing of immobilized AChE caused by pesticides, the composition of pesticide can be determined.

\subsection{Other materials used in biosensor}

Aside from gold nanoparticle and CNTs, there are still various nanomaterials that could be used in biosensor to improve the property due to their nanosize. By using a simple in situ chemical reduction method Platinum nanoparticles (PtNPs) could be attached to glass slide surface [31]. Nano-CuO is used to enhance the electronconductor instead of many other nano-materials and show good catalytic ability to the reduction of $\mathrm{H}_{2} \mathrm{O}_{2}$ [32]. Jiongjia Cheng et al [33]. investigated the promotion effect 


\section{Device designing \\ 2. Design pattern generation on chrome plated glass (Mask making) \\ 3. $\mathrm{SiO}_{2}$ deposition on Si wafer \\ 4. Polisy deposition \\ 5. E-beam; \\ Plasma Etch \\ 6. Photolithography; metallization; Lift-off}
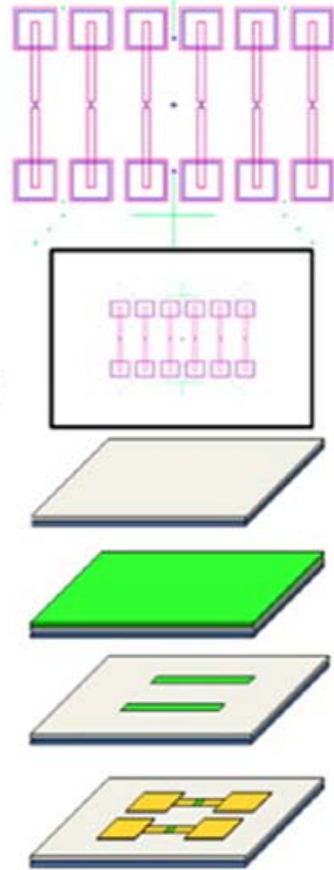

\section{Photolithography Polyimide coat\& baking}

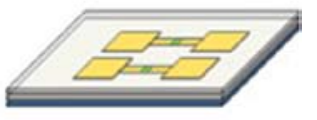

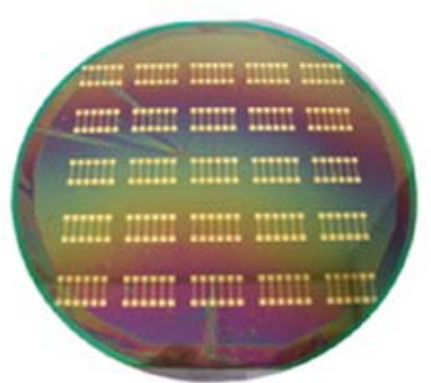

Camera view of device on wafer

Fig. 2 Schematic diagram of process flow involved in nano-FET fabrication[46]

of nano- $\mathrm{TiO}_{2}$ on the direct electron transfer between lactate dehydrogenase and the silica sol-gel modified gold electrode, and this electrode can be used as a biosensor for the determination of lactic acid. With liposome-based nanobiosensors, monitoring of the organophosphorus pesticides dichlorvos and paraoxon at very low levels has been achieved [34]. The nano-sized liposomes provide a suitable environment for the effective stabilization of $\mathrm{AChE}$ and they can be utilized as fluorescent biosensors.

Nanosheet-based $\mathrm{ZnO}$ microsphere with porous nanostructures was synthesized by a facile chemical bath deposition method followed by thermal treatment, which was explored for the construction of electrochemical biosensors [35]. It has been found that the waxberrylike $\mathrm{ZnO}$ balls acted as excellent materials for immobilization of HRP and rapid electron transfer agent for the fabrication of efficient biosensors due to their high electron conductivity, large surface area, increased oxygen vacancies, and good biocompatibility [36].

A 2-dimensional simulation tool was designed to investigate the threshold voltage behaviour for a silicon nanowire constructed in a top down approach on silicon on insulator (SOI) material [37]. The threshold voltage increases with decreasing thickness of the silicon nanowire, which could results in a higher sensitivity for surface charges. Surface functionalized Silicon nanochannels with the enzyme urease could detect and quantify urea concentration [38]. Nanofabricated biosensor from a SOI wafer with a top down lithography approach. The differential conductance of silicon nano-channels can be tuned for optimum performance using the source drain bias voltage, and is sensitive to urea at low concentration. In another work, SOI substrate is used to fabricate the planar type patch clamp ion-channel biosensor, which is suitable for the high throughput screening [39]. The channel current showing the desensitization unique to TRPV1 is measured successfully.

A novel disposable AFP immunosensor is proposed based on HRP/ nano-CdS/Thi +$\} 2 / \mathrm{PCR}$ films modified GCE, The $\{$ nano-CdS/Thi+ 2 bilayer films formed have high electroactivity and stability [40]. Nano-CdS is used to construct the $\{$ nano-CdS/Thi +$\} 2$ bilayer films to result in larger electrode surface area to increase the immobilization of antibodies and improve sensitivity of the immunosensor.

\subsection{Different material structures used in biosensor}

Nanotechnology provides unique nanostructures such as metallic, semiconductor or magnetic nanoparticles, nanowires or nanotubes, exhibiting unique, sizecontrolled, electronic, optical and catalytic properties [41].

Devices based on nanowires have emerged as one of the most powerful and general platforms for ultrasensitive, direct electrical detection of biological and chemical species and for building functional interfaces to biological systems [42]. Fengyan ZHANG et al [43]. demonstrated the feasibility of using a CMOS compatible process in fabricating a submicron $\mathrm{IrO}_{2}$ nanowire array biosensor platform. Biofets (biologically active fieldeffect transistors) are biosensors with a semiconductor transducer. Field-effect biosensors based on planar 
structures and nanowires have been fabricated in recent experiments [44]. Masuhiro Abe et al [45]. showed that an NTFET biosensor can be calibrated using the Langmuir adsorption equation. Living molecules can be quantitatively detected by using any NTFET biosensor without precise control of the CNT growth.Wusi C. Maki et al [46]. reported the first nanowire field effect transistor based biosensor technology which achieves simple and ultra-sensitive electronic DNA methylation detection and avoids complicated bisulfite treatment and PCR amplification, the schematic diagram was showed in Fig. 2. Soon Joon Yoon et al [47]. investigated the target dependence of the sensitivity in a localized surface plasmon resonance biosensor and compare it with that of a conventional thin-film-based plasmon resonance structure. Sensitivity enhancement by LSPR using periodic nanowires has an SEF in the range from zero to over ten for various target interactions in water. And glucose oxidase could be deposited onto the nanowires using self-assembling monolayer as an anchor layer for the enzyme molecules [48].

Poly(ethylene-co-glycidyl methacrylate) (PE-co-GMA) nanofibers with abundant active epoxy groups on surfaces were fabricated through a novel manufacturing process [49].The results demonstrated that PE-co-GMA nanofibers prepared could be a promising candidate as solid support materials for potential biosensor applications. Kh. Ghanbari et al [50]. reported the use of NPV for the synthesis of PPy nanofibers on a platinum electrode. As a new electrochemical biosensor, this electrode is applied to study the interaction of SPD with DNA/PPy nanofiber films.

CdS hollow nanospheres (HS-CdS) are firstly used to study the direct electrochemical behavior of $\mathrm{Hb}$ and the construction of nitrite biosensor [51].The HS-CdS nanostructure provides a microenvironment around the protein to retain the enzymatic bioactivity.

With the use of the boundary element method, a general, practical map of the resonances for use in locating the desired response for gold nanoantennas was provided by calculating the nanorod near-field and far-field response to show how the nanorod shape and dimensions determine its optical response [52].A heterostructured silicon/gold nanorod array fabricated by the glancing angle deposition method is functionalized with anti-Salmonella antibodies and organic dye molecules [53]. This bio-functional hetero-nanorod detection method has great potential in the food safety industry as well as in biomedical diagnostics.

Nanopore detector can be classified by using machine learning techniques such as Hidden Markov Models (HMMs) and Support Vector Machines (SVMs) [54]. These methods provide biologists and chemists a way to get better understanding of the kinetic properties of molecules of interest. By using a nanopore detector, two bifunctional aptamers could be examined [55]. The nanopore detector is biologically based and uses a protein,

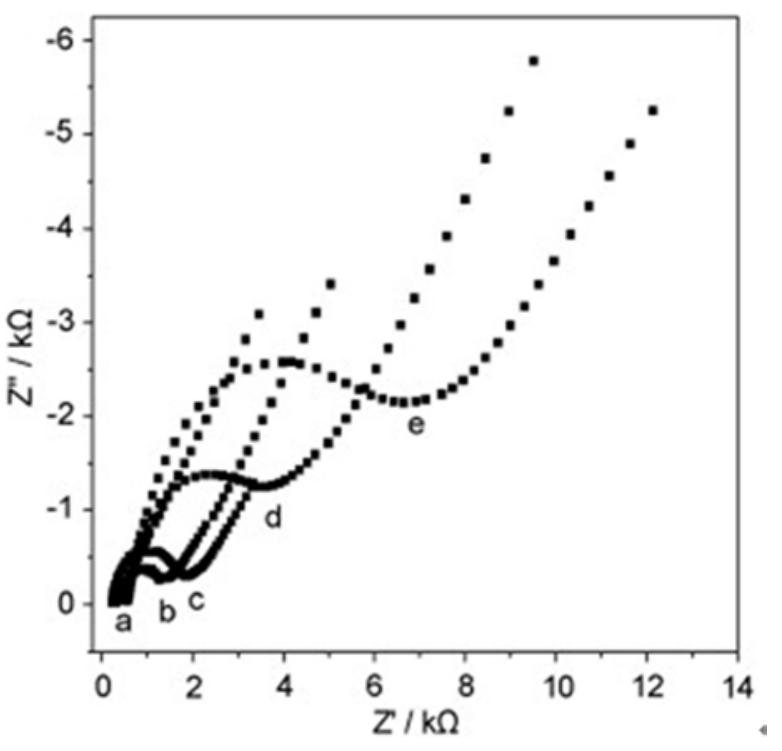

Fig. 3 Electrochemical impedance spectra of (a) bare Au; (b) Cys SAMs/Au; (c) CdTe-Cys SAMs/Au; (d) AChE-CdTe-Cys SAMs/Au and (e) AChE-Cys SAMs/Au recorded at potential of $0.20 \mathrm{~V}$ in $\mathrm{pH} 7.0$ PBS containing $5 \mathrm{mM} \mathrm{K}_{3} \mathrm{Fe}(\mathrm{CN})_{6}$ andK ${ }_{4} \mathrm{Fe}(\mathrm{CN})_{6}[58]$

the $\alpha$-hemolysin $(\alpha-H L)$ toxin produced by the bacterium Staphylococcus aureus, to create a pore through a phospholipid bilayer by self-assembly. Nanoscale tubes provide a higher exposed surface area compared to the flat surface electrodes. A novel approach is to use a nanoporous electrode to fabricate a nanotube array of PPy and thereby enhancing enzyme entrapment [56]. This results a high capacity of enzyme adsorption and enables fast transport of the gaseous by-product.

One of the fastest moving and most exciting interfaces of nanotechnology is the use of quantum dots (QDs) in biology. The unique optical properties of QDs make them appealing as in vivo and in vitro fluorophores in a variety of biological investigations, in which traditional fluorescent labels based on organic molecules fall short of providing long-term stability and simultaneous detection of multiple signals [57]. The nanoparticles of CdTe QDs led to an increased effective surface area for immobilization of enzyme and their electrocatalytic activity promoted electron transfer reactions and catalyzed the electro-oxidation of thiocholine, thus amplifying the detection sensitivity as show in Fig. 3 [58]. Zhengtao Deng et al [59]. reported green and orange CdTe QDs as pHsensitive fluorescent probes could monitor the proton $(\mathrm{H}+)$ flux driven by ATP synthesis for dual simultaneous and independent detection of viruses on the basis of antibodyantigen reactions.

Sungkyu Seo et al [60]. constructed a biochip sensor system, consisting of two Ti contact pads and a $150 \mathrm{~nm}$ wide Ti nanowell device on $\mathrm{LiNbO}_{3}$ substrate, show in Fig. 4. When the bacteria were resistant to the phages (uninfected bacteria), small voltage fluctuations were observed in the nanowell displaying a power spectral density (PSD) of $1 / \mathrm{f}$ shape. 
http://nanobe.org
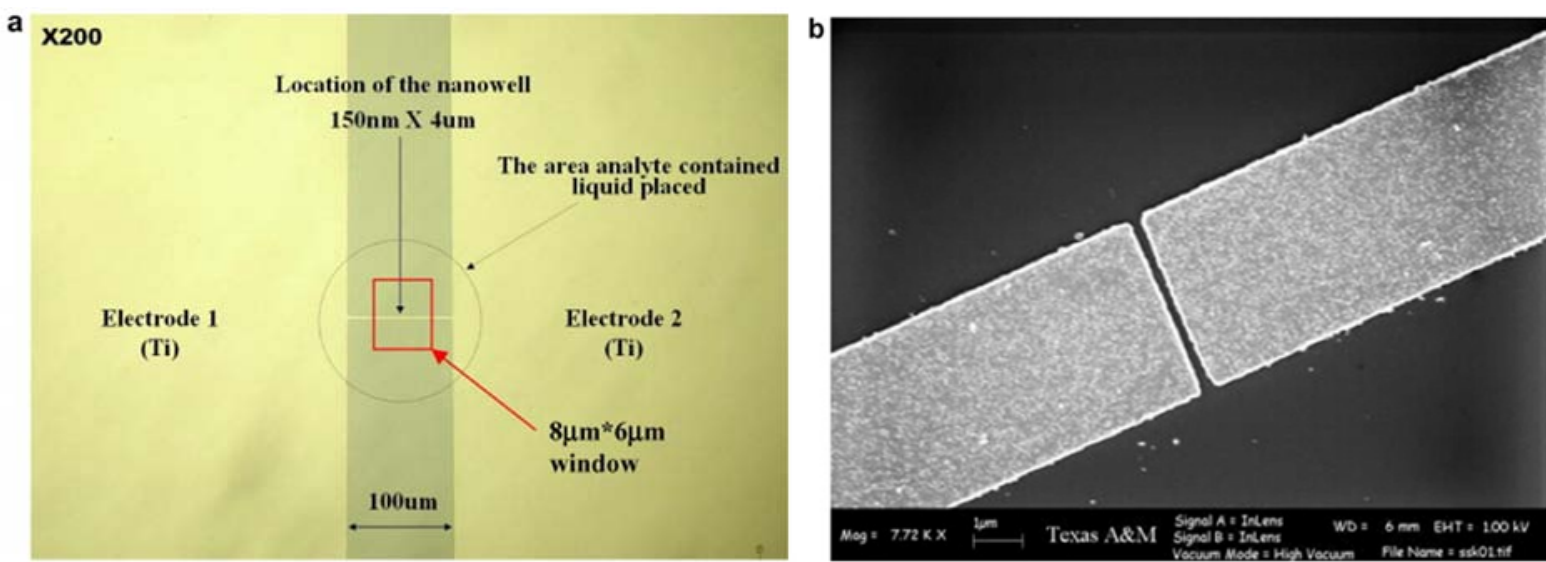

Fig. 4 (a) Optical microscope pictures of the fabricated nanowell device and contact pads $(200 \times)$; (b) SEM picture of the nanowell $(7720 \times)$. To improve image contrast, this nanowell was patterned on silicon substrate. The nanowell used in detecting bacteria/phage was patterned on LiNbO3 substrate [60].

\section{Produce methods of nanobiosesors}

There are different methods to product nanobiosensors for various uses. Here we list some major methods such as magnetism, electrochemical and immune method.

\subsection{Magnetism method}

The nanoscaling laws of magnetic nanoparticles, including metals, metal ferrites, and metal alloys ,are important not only for understanding the behavior of existing materials but also for developing novel nanomaterials with superior properties [61]. A microsphere (MDMS) with uniform shape and narrow diameter distribution has been prepared from magnetic iron nanoparticles and dextran [62].The successfully immobilized of Horseradish peroxidase on the surface of an MDMS-modified GCE lead to a fast response to $\mathrm{H} 2 \mathrm{O} 2$ of less than $10 \mathrm{~s}$ and an excellent linear relationship .A magnetic chitosan microsphere (MCMS) was prepared using carbon-coated iron magnetic nanoparticles and chitosan [63]. Hemoglobin ( $\mathrm{Hb}$ ) was successfully immobilized on the surface of MCMS modified GCE with the cross-linking of glutaraldehyde. And another work reported that planar microcoils and distortion immune bridge measurement allow sensitivity of $8.4 \mathrm{pV} /$ Magnetic nanoparticles [64].Giant magnetoimpedance (GMI)-based biosensing system can achieve the targeted detection of cancer cells $[65,66]$. As show in Fig. 5, is the Scheme of the GMI-based detection system.

\subsection{Electrochemical method}

An electrochemical biosensor is a biosensor with an electrochemical transducer. It is considered a chemically modified electrode (CME) since electronic conducting, semi-conducting or ionic conducting material is coated with a biochemical film [67]. Electrochemical DNA biosensors provide an effective alternative for genetically modified organisms' detection with their advantages of simplicity, low cost, and ease of use [68]. A novel electrochemical DNA biosensor based on zinc
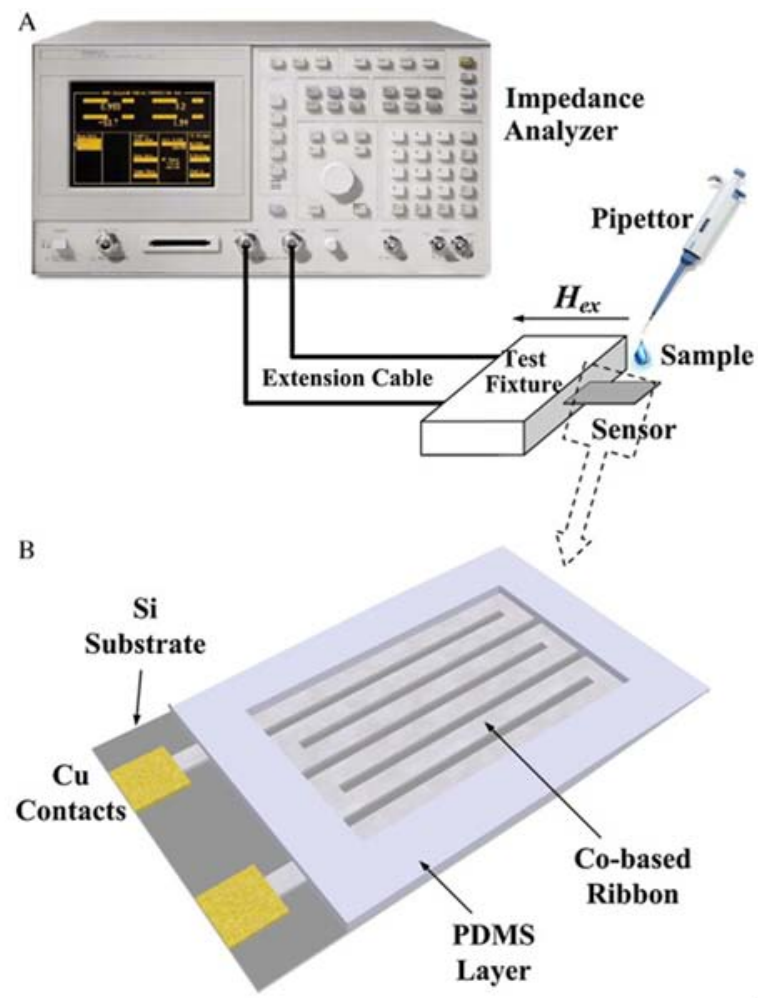

Fig. 5 Scheme of GMI-based detection system: (A) the biosensing system is consist of GMI sensor, a poly dimethylsiloxane (PDMS) mold, an impedance analyzer and a pair of Helmholtz coil; (B) partial magnification of the GMI sensing element.

oxide $(\mathrm{ZnO})$ nanoparticles and multi-walled carbon nanotubes (MWNTs) for DNA immobilization and enhanced hybridization detection is presented [69]. The obtained chitosan-ionic liquid-horseradish peroxidase biocomposite film possessed a porous morphology with orderly three-dimensional network, which possessed high electrocatalytic activity and fast amperometric response to $\mathrm{H}_{2} \mathrm{O}_{2}$.

Elena E et al [70]. reported the first application of an available RNA aptamer as the biorecognition unit as an electrochemical sensor for theophylline. Conformational changes of the aptamer upon binding of the ligand lead to 

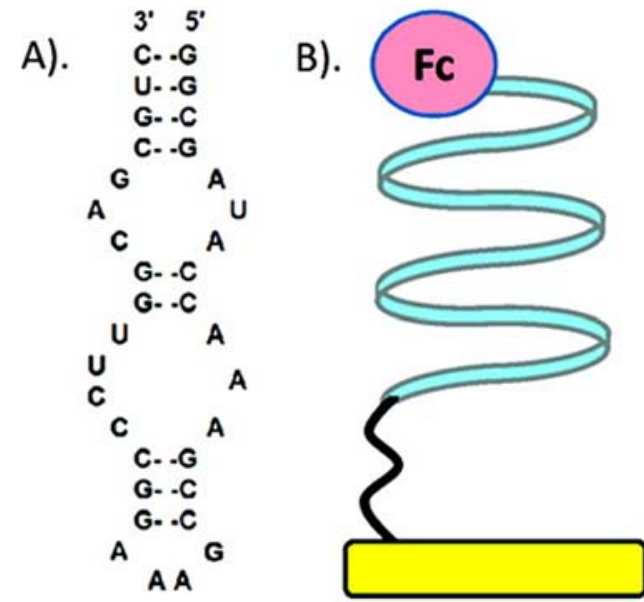<smiles>Cn1c(=O)c2[nH]cnc2n(C)c1=O</smiles>

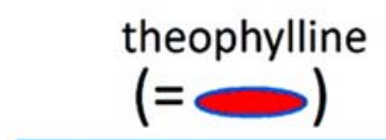

Fig. 6 (a) Theophylline-binding theophylline (Fc ) ferrocene)[68]

a change in either the efficiency of electron transfer (eT) to a redox probe conjugated to the immobilized aptamer or the interfacial eT resistance.

Mingli Yang et al [71]. attempted to use titanate nanotubes (TNTs) as the direct electron transfer promoter to develop a reagentless electrochemical biosensor for lactate detection. Lactate oxidase (LOx) enzyme has been immobilized on the three-dimensional porous TNT network-- offer the pathway for direct electron transfer between the electrode surface and the active redox centers of LOx.

\subsection{Immune method}

As we reviewed at before, gold nanoparticle is widely used in biosensor, especially in immunosensor. Rong Chai et al [72]. assembled gold nanoparticle and MB LBL into films on the GCE modified by thiourea for detection of HCG. Thiourea has two amino groups that the one can be immobilized onto surface of the pretreated GCE and the other can couple gold nanoparticles. Fig. 7 Showed the Schematic illustration of the stepwise immunosensor fabrication process.

In a report, microbeads are used to filter and immobilize antibodies and an immuno-gold silver staining (IGSS) method is used to amplify electrical signals that correspond to the bound antibodies [73]. The chip used for this system is composed of an inexpensive and biocompatible polydimethylsiloxane layer over a Pyrex glass substrate that contains a Pt microelectrode. Fig. 8 showed the analytic concept for the immunoassay. A new concept for coupling an inhibition biosensor immunoassay screening of low molecular weight analytes with nano-liquid-chromatography electrospray ionization time-of-flight mass spectrometry for confirmation of identity using an affinity chip interface has been presented [74].

H.Y. Lee et al [75]. reported a self-organized functional Nano Biomed. Eng. 2011, 3(4), 260-273

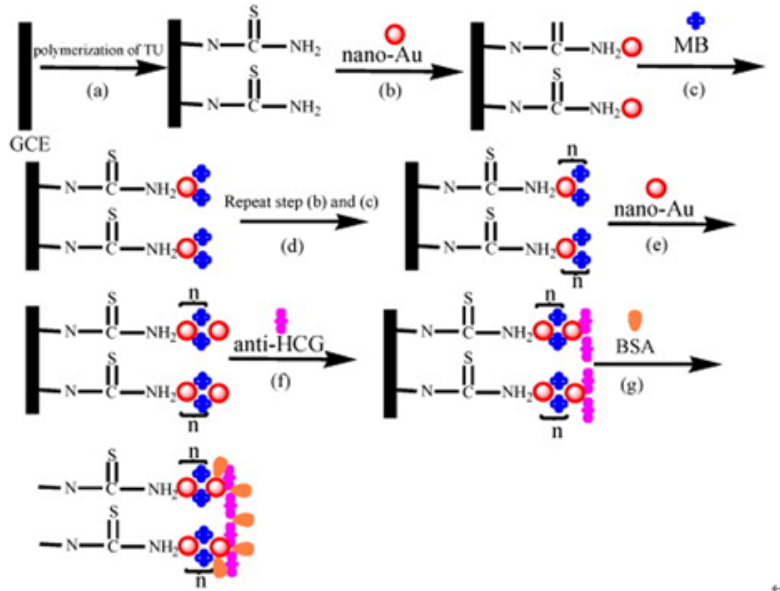

Fig.7 Schematic illustration of the stepwise immunosensor fabrication process: (a) successive CV scanning of TU film; (b) self-assembly of gold nanoparticle monolayer; (c) fabrication of \{gold nanoparticle/MB $\mathrm{n}$ multilayer films, $\mathrm{n}$ denotes the number of the layers; (f) anti-HCG loading; (g) blocking with BSA[70]

lipid vesicles (FLVs) array on nanometrics electrode using electrostatic interaction. The immobilized FLVs maintain their three dimensional configuration. The capture antibody can be immobilized firmly and apparently made to interact specifically with the target antigen.

\subsection{Other methods}

Shihong Chen et al [76]. proposed to immobilize enzyme for the fabrication of reagentless amperometric biosensor. After bounding thionine onto the BSA film, gold nanoparticle was adsorbed onto it to achieve gold nanoparticle/Th-BSA matrix for the immobilization of HRP and then possesses high enzymatic activity, affinity and low detection limit for $\mathrm{H}_{2} \mathrm{O}_{2}$. Ting Cao et al [77]. provided a versatile technique to fabricate chemically immobilized protein patterns by thin-film cracking. The pattern width can be varied from $\sim 250$ to $\sim 2000$ n. Covalently coupled antibody in the channel retains its specificity, and the antibody pattern can reach the saturated status in $10 \mathrm{~min}$. 


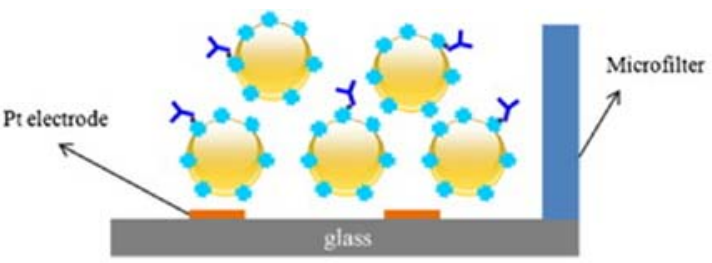

(a)

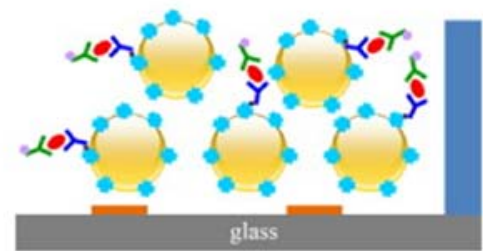

(c)

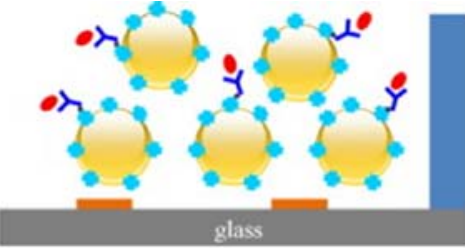

(b)

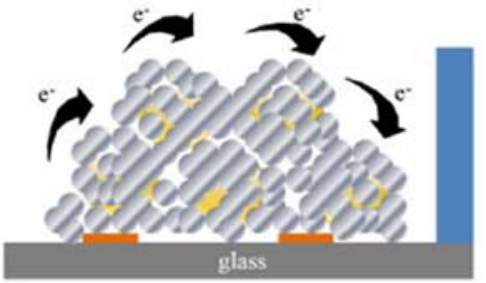

(d)

Streptavidin coated microbead

AFP antigen

Biotinylated capture antibody

Gold conjugated second antibody

Fig. 8 Analytic concept for the electrical immunoassay using microbeads to facilitate the IGSS [72]
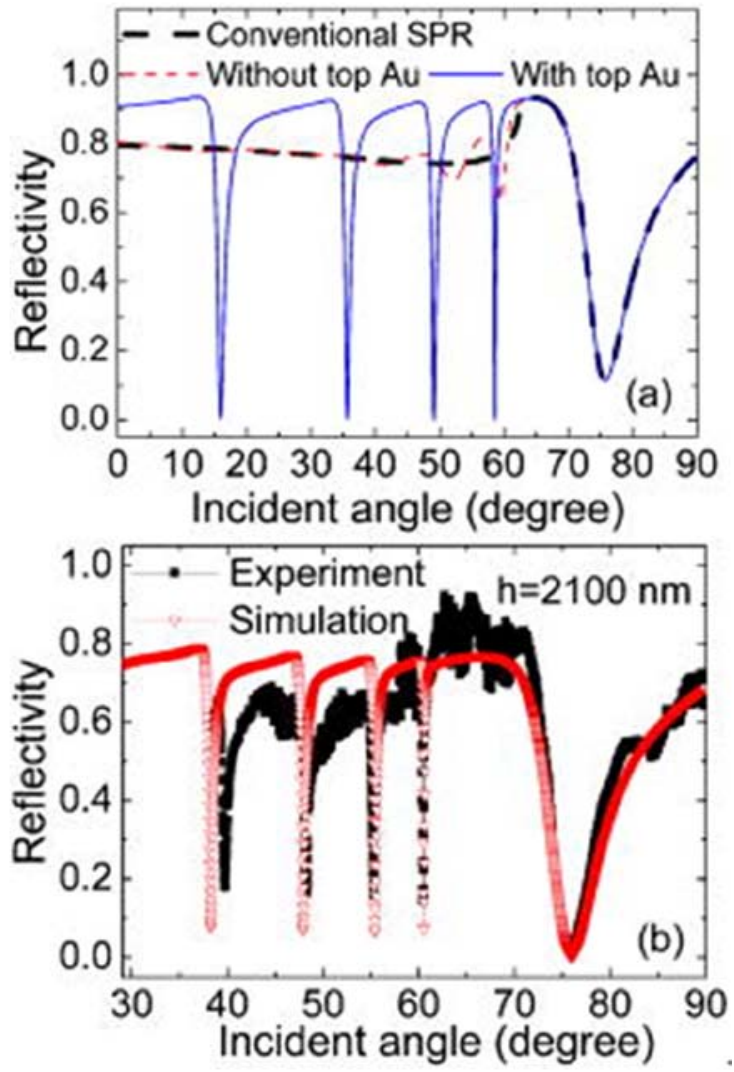

Fig. 9 (a) Comparison of the conventional SPR (dashed black line) and present detection method (blue). To illustrate the importance of the top gold layer, the reflectivity of a channel with bare glass (no gold layer) is also shown (dashed red line). The channel height is $1500 \mathrm{~nm}$, bottom Au thickness is $40 \mathrm{~nm}$, and top Au layer is $100 \mathrm{~nm}$. (b) Measured and calculated resonance curves of the bulk optical modes [79]

Surface plasmon resonance (SPR) is an optical transduction mechanism that demonstrates extremely high sensitivity to surface binding events [78]. It is now regarded as one of the most sensitive direct non-labelled optical sensing techniques for real time monitoring of biological and chemical interactions. SPR images and SPR spectra could be obtained in analyzing protein arrays, because of the novel dual function SPR biosensor which is based on white light [79]. Elisabeth Galopin et al [80]. reported on a proof-of-concept system composed of a droplet based SPR system coupled to a surface acoustic wave microfluidic plateform. It is established that surface based binding analyses are highly influenced by the transport of analyte to the sensing surface. The SPR mode with many bulk modes, could be created in a microfluidic channel with metallic coatings on top and bottom [81] .The bulk modes are bulk sensitive and detect analytes in the channel with 20 times higher sensitivity than the SPR, which is particularly suitable for microfluidic devices (Fig. 9).

\section{Applications of nanobiosensors}

Biosensors have been applied in many fields and the most biosensors are developed for the detection of glucose, special DNA sequence, protein, pesticide and other small molecules. These nanobiosensors have common properties such as high selectivity, sensitivity and accuracy, rapid response.

\subsection{Nanobiosensor for the detection of glucose}

Since biosensors allow a wide range of transduction technology to be used, they have advantage over ordinary chemical sensors. Among them, the glucose biosensor has been widely used as a clinical indicator of diabetes and in the food industry for quality control. Due to its active surface, electrical properties and non-stoichiometric nature, nanostructured tin oxide plays an important role 

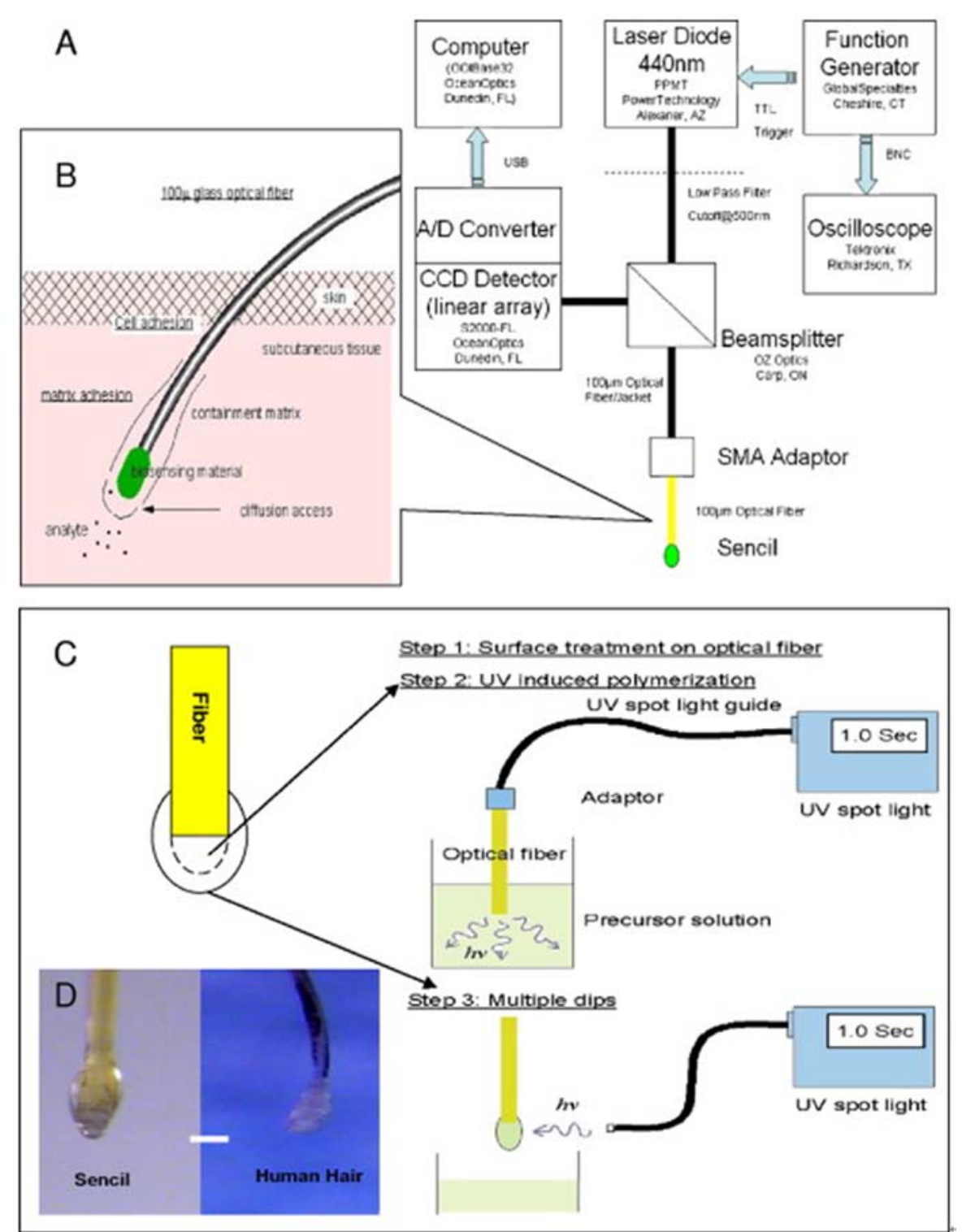

Fig. 10 Basic components and fabrication of Sencil prototype. (a) Laboratory spectroscopic instrumentation used to test prototypes; similar functionality must be miniaturized for portable clinical reader. (b) Sensor components and relationships to tissue in vivo. (c) Scheme of manufacture method with adhesion enhancement. (d) Similarity of shape and size between Sencil and human hair with attached follicle (white bar $=100 \mu \mathrm{m})[86]$.

in glucose sensor performance [82]. Bo-Wen Lu et al [83]. introduced an approach for fabrication of glucose biosensor based on drop-coating glucose oxidase on screen-printed carbon electrodes modified with FerriNano- $\mathrm{Fe}_{3} \mathrm{O}_{4}$ mixture. And glucose biosensor with PQQ$\mathrm{GDH} /$ ferricyanide/CNTs on a screen-printed carbon paste electrode exhibited a sensitivity of $31.0 \mu \mathrm{A} \mathrm{mM} \mathrm{mM}^{-1} \mathrm{~cm}^{-2}$ to glucose with a linear range of $1-35 \mathrm{mM}$ as well as only $2 \mu \mathrm{l}$ volume and $20 \mathrm{~s}$ to response [84]. The mediator ferricyanide realized the electron transfer between the enzyme and electrode surface.

Fibrous morphology and wrapping of PDDA over MWCNTs result in a high loading of GOx into the electrospun matrix [85]. Pt nanoparticles could be electrodeposited on MWNTs matrix in a simple and robust way. The immobilization of glucose oxidase onto Pt/MWNTs electrode surfaces also could be carried out by chitosan- $\mathrm{SiO}_{2}$ gel. The good results may be attributed to the synergistic action of Pt and MWNTs and the good biocompatibility of chitosan- $\mathrm{SiO}_{2}$ sol-gel [86]. J.J YU et al [87]. fabricated a glucose biosensor based on GOx immobilized in Pt/CMK-3 matrix. With an extra Nafion film to eliminate the interferents, the resulting biosensor could be used to determine the glucose levels of serum samples.

S.G. Ansari et al. are developing a family of fiberoptic sensors called Sencils ${ }^{\mathrm{TM}}$ (sensory cilia), which can provide in vivo monitoring of various analytes for several weeks. The key element is a chronically implanted optical fiber (Fig. 10) with size and flexibility similar to a human hair and perfect fiber communication technology.[88] .And the illustration of glucose assay system is shown in Fig. 11 . 


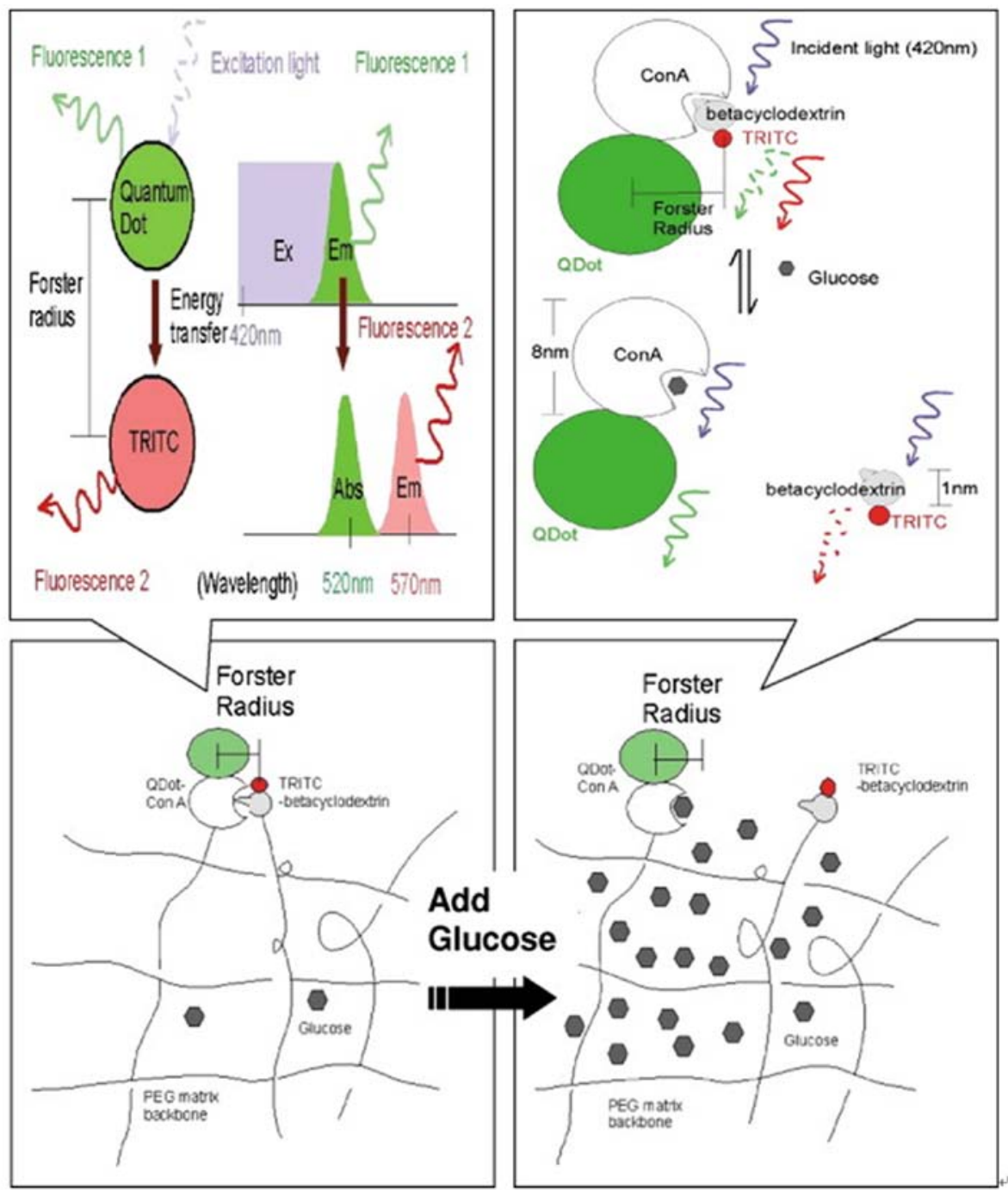

Fig. 11 Illustration of glucose assay system. Changes in FRET between fluorophores covalently immobilized on the flexible PEG matrix depend on changes in the distance between them, which in turn depends on the competitive natural affinity between Con A and various saccharides such as betacyclodextrin and glucose [86].

The classical method of glucose sensing involves the monitoring of $\mathrm{H}_{2} \mathrm{O}_{2}$ production by amperometric measurements. However, the requirement of a high positive potential $(\sim 0.6 \mathrm{~V}$ vs. $\mathrm{Ag} / \mathrm{AgCl})$ in this method leads to interference with other chemical species that influence the precise determination of the glucose concentration. Akira Kusakari et al [89]. demonstrated ODTA/PB/GOx LB films show a typical glucose sensor action at the potential of $0.0 \mathrm{~V}$ (vs. $\mathrm{Ag} / \mathrm{AgCl}$ )(Fig. 12).

\subsection{Nanobiosensor for the detection of DNA and protei}

Sequencing of the human genome opened the way to the exploration of the proteome and this has lead to the identification of large numbers of proteins in complex biological samples. The solution of many of the technical challenges in proteomics and protein based molecular diagnostics will be found in new applications of nonmaterial [90]. Microcantilevers convert intermolecular reaction forces to detectable cantilever deflection in nanometers. Shi $\mathrm{H}$ et al [91]. first highlight the concept of coordinated nanobiosensors, which integrate desirable properties of the individual components: protein machinery for sensitivity and specificity of binding, peptide or nucleic acid chemistry for aligning the various electron-transducing units and the nanoelectrodes for enhancing sensitivity. Min Yue et al [92]. demonstrated label-free antibody-antigen binding assays by optically detecting nanoscale motions of two-dimensional arrays of microcantilever beams. Prostate specific antigen was assayed using antibodies covalently bound to one surface of the cantilevers by two different surface chemistries.

A biosensor for the detection of deep DNA damage is designed employing the bionanocomposite layer of MWNT in chitosan deposited on a SPCE [93].The biocomponent represented by double-stranded herring sperm DNA was immobilized on this composite using layer-by-layer coverage to form a robust film. Another biosensor employing immobilized DNA on a nanostructured conductive polymer fixed onto a platinum 


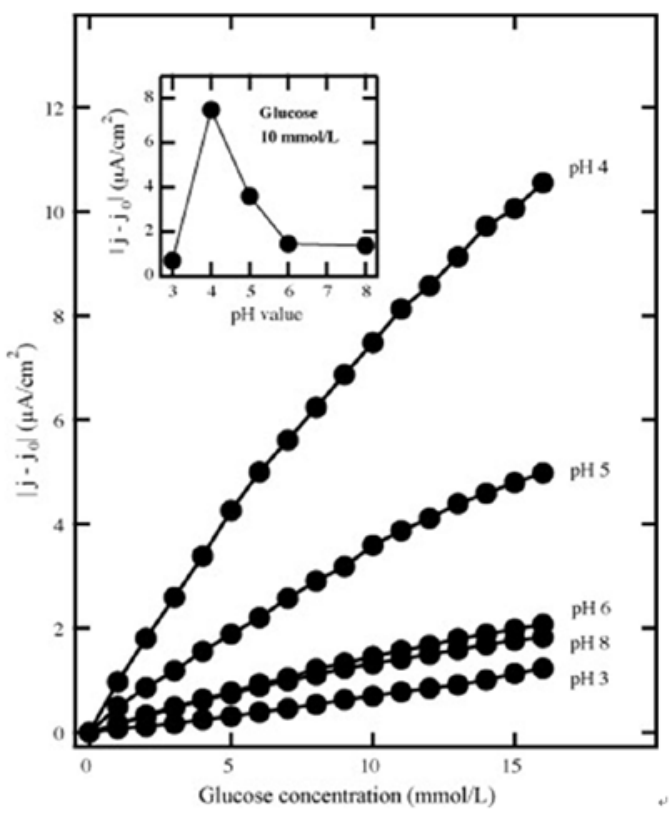

Fig. 12 Plots of response current density versus glucose concentration for the LB films (6 layers) prepared at different $\mathrm{pH}$ GOx solutions. The inset shows the current density at the fixed glucose solution of $10 \mathrm{mmol} /$ $\mathrm{L}$ as a function of the $\mathrm{pH}[87]$.

electrode is presented as a new electrochemical sensor. Polypyrrole nanofibers, 30-90 $\mathrm{nm}$ in diameter, were synthesized in an aqueous media by the electropolymerization of pyrrole using normal PV. Double stranded DNA was physisorbed onto the PPy nanofiber films [94]. And for single-stranded DNA, gold nanoparticles functionalized with alkanethiol-capped LNA/DNA chimeras in a tail-to-tail hybridization mode could perform excellent [95]. and these probes show remarkable discrimination between a complementary target and one containing a single-base mismatch. Nano$\mathrm{SiO}_{2} / \mathrm{p}$-aminothiophenol (PATP) film was fabricated by self-assembly and electrodeposition methods and was successfully applied to the detection of the PAT gene sequences by a label-free EIS method [96]. Wei Zhang et al [97]. fabricated a MWNTs/nano ZnO/ chitosan composite film modified GCE and immobilized DNA probes on the electrode surface. The sensor can effectively discriminate different DNA sequences related to PAT gene in the transgenic corn, with a detection limit of $2.8 \times 10^{-12} \mathrm{~mol} / \mathrm{L}$ of target sequence.

\subsection{Other applications of nanobiosensors}

The liposome-based nanobiosensor could be used for the detection of organophosphorus pesticides. Porins embedded into the lipid membrane allow for the free substrate and pesticide transport into the liposomes. Pesticide concentrations down to $10^{-10} \mathrm{~mol} \mathrm{~L}^{-1}$ can be monitored using this inhibition fluorescent biosensor [98] . A work describes an approach for substrate integrating enzyme activation and corresponding current response at the substrate-bound enzyme electrode. Tyrosinase was activated by the use of reduced pyrroloquinoline quinone which was covalently bonded with the modified gold nanoparticles, which enhanced the sensitivity [99] .Another paper presented the chemistry of a deposited enzymatic layer (acethylcholinesterase(AChE) enzyme). The membrane is obtained by drying the gel in air flow and loosing of water molecules facilitates the enzyme accessibility to the support linking sites, by the interactions between the rest of polar and non-polar amino acids, ionic forces, hydrogen bridges and van der Waals forces [100].

Yuanbiao Qiao et al [101]. reported the facile electrochemistry of the $\mathrm{Mb}-\mathrm{Zr}(\mathrm{UMP})_{2} \cdot \mathrm{H}_{2} \mathrm{O}$ film on the GCE and the application to $\mathrm{H}_{2} \mathrm{O}_{2}$ biosensor. Porous nano-granule of zirconium uridine monophosphate, $\mathrm{Zr}(\mathrm{UMP})_{2} \cdot \mathrm{H}_{2} \mathrm{O}$ is synthesized under mild experimental conditions and applied to the bioconjugation of myoglobin $(\mathrm{Mb})$ to realize its direct electron transfer. The linear range for $\mathrm{H}_{2} \mathrm{O}_{2}$ detection is estimated to be 3.92 $180.14 \mu \mathrm{M}$.

Hongying Zhu et al [102]. developed an optical sensor for on-line virus detection based on the opto-fluidic ring resonator has been developed. Microfabricated waveguides will be employed in replacement of the fiber taper to realize the microarray chip for detecting and analyzing multiple viruses in a parallel manner. Colin D. Medley et al [103]. developed a colorimetric assay for the direct detection of diseased cells. This assay uses aptamerconjugated gold nanoparticles to combine the selectivity and affinity of aptamers and the spectroscopic advantages of gold nanoparticles. Samples with diseased cells present exhibited a distinct color change while nontarget samples did notas shown in Fig. 13.

Mitochondrial oxidative stress has been hypothesized as one of the earliest insults in diabetes. Some data support the hypothesis that the induction of MOS is more sensitive to hyperglycemia than the induction of the antioxidant response element (ARE). Delivery of an ARE-GFP construct with nanoparticles to the eye was successful using sub-retinal injection [104]. These data support the use of nanoparticle-delivered biosensors for monitoring the oxidative status of tissues in vivo.

Bingling Li et al [105]. reported an electrochemical aptasensor for adenosine based on impedance spectroscopy measurement, which gives not only a labelfree but also a reusable platform to make the detection of small molecules simple and convenient. The method proposed did not rely on the molecule size or the conformational change of the aptamer.

The structure of Photonic crystals $(\mathrm{PhC})$ depicted in Fig. 13 ,which is patterned using electron beam lithography on a siliconon-insulator wafer with a Si slab thickness of 400 $\mathrm{nm}$. It also has shown that a Si 2-D PhCbased sensor can be used for detecting single particles that have a diameter

O'dho5T 269 
http://nanobe.org
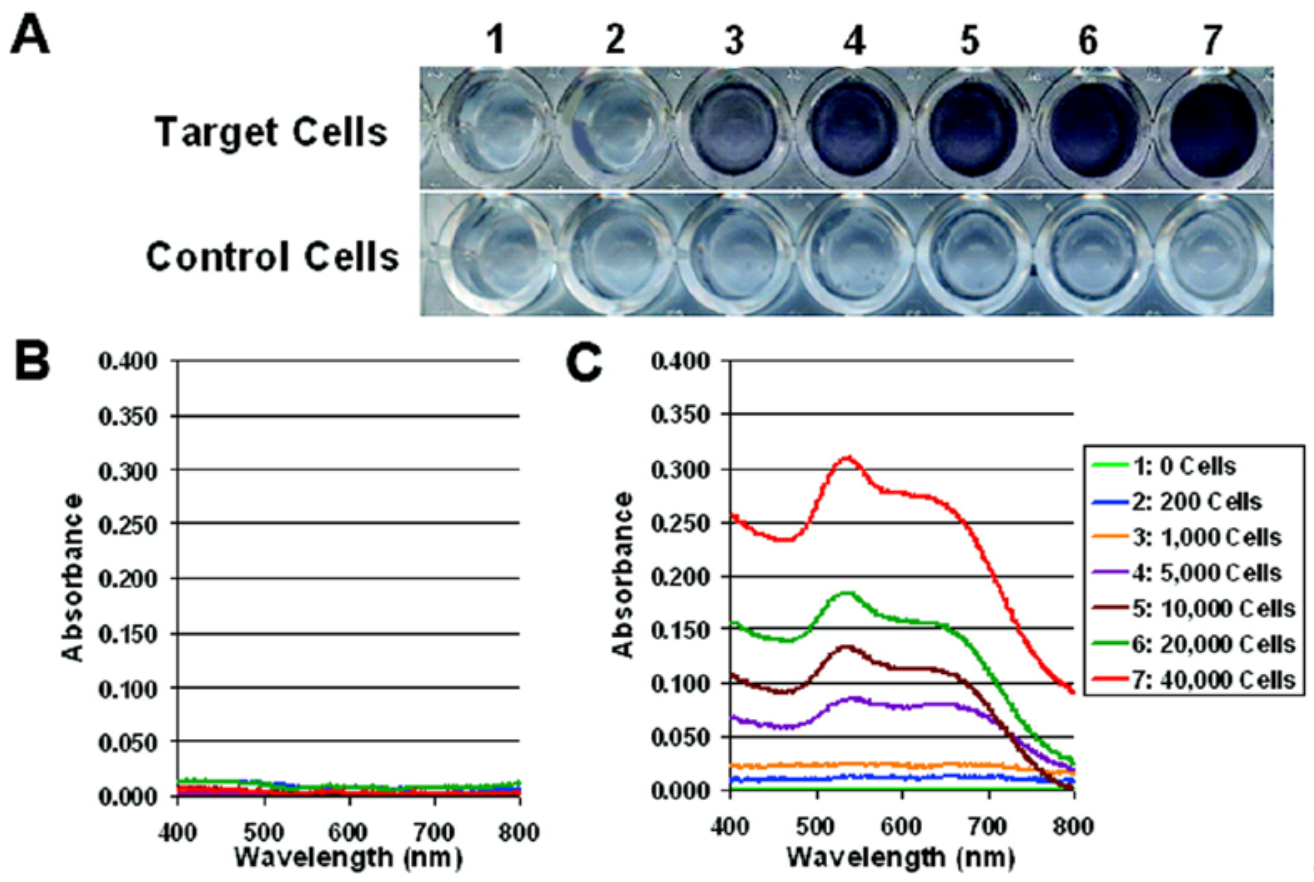

Fig. 13 (a) Images of ACGNPS with increasing amounts of target (top) and control cells (bottom). The amount of cells used in each sample is given in the legend on the bottom right. (b) Absorption spectra of the control cell samples with ACGNPs in Figure A. (c) Absorption spectra of the target samples with ACGNPs in Figure A [101].

of $<50 \mathrm{~nm}$. After proper functionalization, the device should be able to detect single viral pathogens such as severe acute respiratory syndrome [106].

\section{Conclusions}

The interdisciplinary cross of nanotechnology and biosciences opens the possibility for a wide variety of biological applications. Nanomaterials have shown numerous unique physical, chemical, electronic, and optical properties. We believe that nanotechnology used to biosensor will improve biomedical diagnostics and therapy.

\section{References}

1 .Reshetilov N and Bezborodov AM. Nanobiotechnology and BiosensorResearch. Applied Biochemistry and Microbiology. 2008; 44:1-5. http://dx.doi.org/10.1134S0003683808010018

2 .Viswanathan S, Radecki J. Nanomaterials in electrochemical biosensorsfor food analysis û a review. Polish Journal of Food and Nutrition Sciences year. 2008; 58(2):157-164

3.Katz E, Willner I, Chem J. Electroana1.2004;16:19. http://dx.doi.org/10.1002/elan.200302930

4.Chen RS,Huang WH,Tong H,Wang ZL,Cheng JK. Anal. Chem. 2003;75:6341. http://dx.doi.org/10.1021/ac0340556

5. Valentini F, Amine A.,Orlanducci S,Terranova ML,Palleschi G. Anal. Chem.2003;75:5413. http://dx.doi.org/10.1021/ac0300237

6. Liang KZ, Qi JS, Mu WJ, Chen ZG. Biomolecules/gold nanowiresdoped sol-gel film for label-free electrochemical immunoassay of testosterone. Biochem.Biophys.Methods. 2008;70:1156-1162. http:// dx.doi.org/10.1016/j.jprot.2007.11.007

7. HeXL, Yuan R, Chai YQ,Shi Y T. A sensitive amperometric immunosensor for carcinoembryonic antigen detection with porous nanogold film and nano-Auchitosan composite as immobilization matrix. Biochem.Biophys.Methods.2008;70: 823-829. http://dx.doi.org/10.1016/j.jbbm.2007.06.002
8 Kim GY,Shim J,Kang MS,Moon SH .Optimized coverage of gold nanoparticles at tyrosinase electrode for measurement of a pesticide in various water samples. Journal of Hazardous Materials. 2008; 156:141-147. http://dx.doi.org/10.1016/j.jhazmat.2007.12.007

9.Asowicz M,Viswanathan S,Dvornyk A , Krystyna Grzelak, Barbara Kłudkiewicz, Hanna Radecka, Comparisonof electrochemical immunosensors based on gold nano materials and immunoblot techniques for detection of histidine-tagged proteins in culture medium. Biosensors and Bioelectronics. 2008;24:284-289. http://dx.doi:10.1016/j.bios.2008.04.002

$10 \mathrm{Jena} B K, \mathrm{Raj}$ CR. Optical sensing of biomedically important polyionic drugs using nano-sized gold particles. Biosensors and Bioelectronics.2008;23:1285-1290. http://dx.doi.org/10.1016/ j.bios.2007.11.014

11.Zhao W, Chiuman W, Lam JC, Brook MA, Li Y. Simple and rapid colorimetric enzyme sensing assays using non-crosslinking gold nanoparticle aggregation. Chem.Commun. 2007;3729-3731. http://dx.doi.org/10.1039/b705335e

12Wei H,Li Bl,Li J,WangE, andDongSJ Simple and sensitive aptamerbased colorimetric sensing of protein using unmodified gold nanoparticle. Chem.Commun. 2007;3735-3737. http://dx.doi. org/10.1039/b707642h

13Zheng Y, Lin XQ. Modified Electrode Based on Immobilizing Horseradish Peroxidase on nano-Gold with Choline Covalently Modified Glassy Carbon Electrode as a Base. Chin J AnalChem. 2008;36(5):604-608. http://dx.doi.org/10.1016/S18722040(08) 60034-1

14.Chai R,Yuan R,Chai YQ,Ou CF,Cao SR, Li XL, Amperometric immunosensors based on layer-by- layer assembly of gold nanoparticles and methylene blue on thiourea modified glassy carbon electrode for determination of human chorionic gonadotrophin. Talanta. 2008;74:1330-1336. http://dx.doi. org/10.1016/j.talanta.2007.08.046

15.Li NB,Park JH,Park K,Kwon SJ, Shin H,Kwak J. Characterization and electrocatalytic properties of Prussian blue electrochemically deposited on nano-Au/PAMAM dendrimer-modified gold electrode. Biosensors and Bioelectronics. 2008;23:1519-1526. http://dx.doi. org/10.1016/j.bios.2008.01.009

16.Shi AW,Qu FL, Yang MH,Shen GL, Yu RQ. Amperometric $\mathrm{H}_{2} \mathrm{O}_{2}$ biosensor based on poly-thionine nanowire/HRP/nano-Au-modified glassy carbon electrode. Sensors and ActuatorsB. 2008;129:779- 
783. http://dx.doi.org/10.1016/j.snb.2007.09.062

17.Cui RJ ,Huang HP, Yin ZZ, Gao D,Zhu JJ .Horseradish peroxidasefunctionalized gold nanoparticle label for amplified immunoanalysis based on gold nanoparticles/carbon nanotubes hybrids modified biosensor. Biosensors and Bioelectronics. 2008;23:1666-1673. http://dx.doi.org/10.1016/j.bios.2008.01.034

18.MinWang, Zhuyun Li. Nano-composite $\mathrm{ZrO} 2 / \mathrm{Au}$ film electrode for voltammetric detection of parathion. Sensors and Actuators B. 2008;133:607-612.http://dx.doi:10.1016/j.snb.2008.03.023

19. Manesh KM, Kim HT ,Santhosh P ,Gopalan AI, Lee KP. A novel glucose biosensor based on immobilization of glucose oxidase into multiwall carbon nanotubes-polyelectrolyte- loaded electrospun nanofibrous membrane. Biosensors and Bioelectronics. 2008;23: 771-779. http://dx.doi.org/10.1016/j.bios.2007.08.016

20.Zeng JX, Wei WZ, Liu XY, Wang Y, Luo GM. A simple method to fabricate a Prussian Blue nanoparticles/carbon nanotubes/poly(1,2diaminobenzene) based glucose biosensor. Microchim Acta.2008; 160:261-267. http://dx.doi.org/10.1007/s00604-007-0818-8

21. Muguruma H, Shibayama Y, Matsui Y. An amperometric biosensor based on a composite of single-walled carbonnanotubes, plasmapolymerized thin film, and an enzyme. Biosensors and Bioelectronics 2008;23: 827-832. http://dx.doi.org/10.1016/ j.bios.2007.08.024

22.Li G, Xu H, Huang WJ, Wang Y, Wu YS, Parajuli R. A pyrrole quinoline quinone glucose dehydrogenase biosensor based on screenprinted carbon paste electrodes modified by carbon nanotubes. Meas. Sci.Technol. 2008;19:065203.

23. Muguruma H,Shibayama Y, Matsui Y, An amperometric biosensor based on a composite of single-walled carbonnanotubes, plasmapolymerized thin film, and an enzyme. Biosensors and Bioelectronics. 2008;23:827-832. http://dx.doi.org/10.1016/ j.bios.2007.08.024

24.Galandova J,Ziyatdinova G and Labuda J.Disposable Electrochemical Biosensor with Multiwalled Carbon NanotubesChitosan Composite Layer for the Detection of Deep DNA Damage. Analytical Sciences. 2008;24(6):711.

25.Zhang W, Yang T, Huang DM, Jiao K.Electrochemical sensing of DNA immobilization and hybridization based on carbon nanotubes/nano zinc oxide/chitosan composite film. Chinese Chemical Letters. 2008;19:589-591. http://dx.doi.org/10.1016/ j.cclet.2008.03.012

26. Weeks ML, Rahman T, Frymier PD, Islam SK, McKnight TE. A eagentless enzymatic amperometricbiosensor using vertically aligned carbon nanofibers (VACNF). Sensors and Actuators B. 2008;133: 53-59

27.Bai HP,Lu XX,Yang MM,Yang YH. Hydrogen peroxide biosensor based on electrodeposition of zinc oxide nanoflowers onto carbon nanotubes film electrode. Chinese Chemical Letters. 2008;19:314318. http://dx.doi.org/10.1016/j.cclet.2007.12.030

28.Zhang SH, Shan LG, Tian ZR, Zheng Y,Shi LY, Zhang DS. Study of enzyme biosensor based on carbon nanotubes modified electrode for detection of pesticides residue. Chinese Chemical Letters. 2008;19:592-594. http://dx.doi.org/10.1016/j.cclet.2008.03.014

29.Liu G, Lin Y. Amperometric glucose biosensor based on elf-assembling glucose oxidase on carbon nanotubes. Electrochem. Commun. 2006;8:251.http://dx.doi.org/10.1016/j.elecom.2005.11.015

30.Zhao H, Huang J. Multilayer membranes for glucose biosensing via layer-by-layer assembly of multiwall carbon nanotubes and glucose oxidase. Anal. Biochem. 2006;350:138. http://dx.doi. org/10.1016/j.ab.2005.11.034

31.Yang MH, Qu FL, Lu YS, Shen GL, Yu RQ. In situ chemical reductive growth of platinum nanoparticles on glass slide for the mass fabrication of biosensors. Talanta. 2008;74:831-83. http://dx.doi.org/10.1016/j.talanta.2007.07.013

32. Miao XM, Yuan R*, Chai YQ, Shi YT, Yuan YY. Direct electrocatalytic reduction of hydrogen peroxide based on Nafion and copper oxide nanoparticles modified Pt electrode. Journal of Electroanalytical Chemistry. 2008;612:157-163

33Cheng JJ, Di JW, Hong JH, Yao K, Sun Y, Zhuang JY. Thepromotion effect of titania nanoparticles on the direct electrochemistryof lactate dehydrogenase sol-gel modified gold electrode. Talanta. 2008;76:1065-1069. http://dx.doi:10.1016/j.talanta. 2008.05.006

34.Vamvakaki V, Chaniotakis NA. Pesticide detection with a liposome-based nano-biosensor. Biosensors and Bioelectronics.
2007;22:2848-2853. http://dx.doi.org/10.1016/j.bios.2006.11.024

35.Lu XB, Zhang HJ, Ni YW, Zhang Q, Chen JP. Porous nanosheetbased $\mathrm{ZnO}$ microspheres for the construction of direct electrochemical biosensors. Biosensors and Bioelectronics. 2008;24:93-98. http://dx.doi:10.1016/j.bios.2008.03.025

36. Cao X, Ning W, Li LD, Guo L. Synthesis and characterization of waxberry-like microstructures $\mathrm{ZnO}$ for biosensors. Sensors and Actuators B. 2008;129:268-273. http://dx.doi.org/10.1016/j.snb. 2007.08.003

37.Elfström $1 \mathrm{~N}$ and Linnros J. Sensitivity of silicon nanowires in biosensor applications. Journal of Physics: Conference Series. 2008;100:052042. http://dx.doi.org/10.1088/17426596/100/5/052042

38.Chen Y, Wang XH, Hong M, Erramilli S, Mohanty P. Surfacemodified silicon nano-channel for urea sensing. Sensors and Actuators B. 2008;133:593-598. http://dx.doi:10.1016/j.snb. 2008.03.033

39.Zhang ZL, Asano T, Uno H, Tero R,Suzui M, Nakao S. Fabrication of Si-based planar type patch clamp biosensor using silicon on insulator. Thin Solid Films. 2008;516:2813-2815. http://dx.doi.org/10.1016/j.tsf.2007.04.104

40.Miao XM, Yuan R, Chai YQ, Shi YT, Yuan YR. Electrochemical immunoassay for -1-fetoprotein based on CdS nanoparticles and Thionine bilayer films modified glass carbon electrode. Biochemical Engineering Journal. 2008;38:9-15. http://dx.doi.org/10.1016/ j.bej.2007.05.015

41Willner I. Nanobiotechnology. FEBS Journal. 2007;274:301. http://dx.doi.org/10.1111/j.1742-4658.2006.05601.x

42.Patolsky F, Timko BP, Zheng GF and Lieber CM. Nanowire Based Nanoelectronic Devices in the Life Sciences. Mrs Blletin. 2007;32(2);142-149. http://dx.doi.org/10.1557mrs2007.47

43.Zhang FY, Ulrich B, Reddy RK, Venkatraman VL, Prasad S, VU TQ. MFabrication of Submicron $\mathrm{IrO}_{2}$ Nanowire Array Biosensor Platform by Conventional Complementary Metal-OxideSemiconductor Process. Japanese Journal of Applied Physics. 2008;47(2):1147-1151

44.Heitzinger C, Kennell R, Klimeck G, Mauser N, McLennan M and Ringhofer C, Modeling and simulation of field-effect biosensors (BioFETs) and their deployment on the nanoHUB. Journal of Physics: Conference Series. 2008;107:012004. http://dx.doi. org/10.1088/1742-6596/107/1/012004

45.Abe M, Murata K, Ataka T,Matsumoto K. Calibration method for a carbon nanotube field-effecttransistor biosensor. Nanotechnology. 2008; $19 ; 045505$

46.Maki WC, Mishra NN, Cameron EG, Filanoski B, Rastogi SK Maki GK. Nanowire-transistor based ultra-sensitive DNA methylation detection. Biosensors and Bioelectronics.2008;23; 780-787. http://dx.doi.org/10.1016/j.bios.2007.08.017

47. Yoon SJ and Kim D.Target dependence of the sensitivity in periodic nanowire-based localized surface plasmon resonance biosensors. Virtual Journal for Biomedical Optics.3(4).

48. Curulli $\mathrm{A}$ and Zane D. Gold and $\mathrm{TiO}_{2}$ Nanostructurated Surfaces for Assembling of Electrochemical Biosensors. Research Letters in Nanotechnology Volume. 2008;4:789153.

49. Wang D, Sun G, Xiang B, Chiou BS. Controllable biotinylated poly(ethylene-co-glycidyl methacrylate) (PE-co-GMA) nanofibers to bind streptavidin-horseradish peroxidase (HRP) for potential biosensor applications. European polymer journal. 2008;44(7):2032.

50.Ghanbari KH, Bathaie SZ. Mousavi MF, Electrochemically fabricated polypyrrole nanofiber-modified electrode as a new electrochemical DNA biosensor. Biosensors and Bioelectronics. 2008;23:1825-1831. http://dx.doi.org/10.1016/j.bios.2008.02.029

51.Dai ZH, Bai HY, Hong M, Zhu YY, Bao JC, Shen J. A novel nitrite biosensor based on the direct electron transfer of hemoglobin immobilized on CdS hollow nanospheres. Biosensors and Bioelectronics. 2008;23:1869-1873. http://dx.doi.org/10.1016/ j.bios.2008.03.002

52.Bryant GW, Javier Garcı'a de Abajo F and Aizpurua J. Mapping the Plasmon Resonances of Metallic Nanoantennas. Nano Lett. 2008 ; 8(2):631-6. http://dx.doi.org/10.1021/n1073042v

53.Fu J, Park B, Siragusa G, Jones L, Tripp R,Zhao YP and Cho YJ. $\mathrm{An} \mathrm{Au} / \mathrm{Si}$ hetero-nanorod-based biosensor for Salmonella detection. Nanotechnology. 2008;19:155502.

54.Landry $\mathrm{M}$ and Winters-Hilt S. Analysis of nanopore detector 
measurements using Machine-Learning methods, with application to single-molecule kinetic analysis. BMC bioinformatics. 2007;8(7):12

55.Thomson K, Amin I, Eric M,Stephen WH. Preliminary nanopore cheminformatics analysisof aptamer-target binding strength. BMC bioinformatics. 2007;8(Suppl 7):S11. http:// doi:10.1186/1471-21058-S7-S11

56.Mala Ekanayake EMI, Preethichandra DMG, Kaneto K. Polypyrrole nanotube array sensor for enhanced adsorption of glucose oxidase in glucose biosensors. Biosensors and Bioelectronics. 2007;23:107-113. http://dx.doi.org/10.1016/j.bios.2007.03.022

57. Medintz IL, Teysuo Uyeda H, Goldman E and Mattoussi H. Quantum dot bioconjugates for imaging, labelling and sensing. Nat Mater. 2005;4(6):435-446. http://dx. doi:10.1038/nmat1390

58.Du D, Chen WJ, Cai J, Zhang J, Qu FG and Li HB. Development of acetylcholinesterase biosensor based on CdTe quantum dots modified cysteamine self-assembled monolayers. Journal of Electroanalytical Chemistry. 2008;623(1):81-85.

59.Deng ZT, Zhang Y, Yue JC,Tang FQ and Wei Q. Green and Orange CdTe Quantum Dots as Effective $\mathrm{pH}-$ SensitiveFluorescent Probes for Dual Simultaneous and Independent Detectionof Viruses. Phys Chem.B. 2007;111(41):12024-12031. http://dx.doi.org/10.1021/ jp074609z

60.Seo S, Maria DK, Young RF, Kish LB,Cheng M. Patterning a nanowell sensor biochip for specific and rapid detection of bacteria Microelectronic Engineering. 2008;85:1484-1489. http://dx.doi. org/10.1016/j.mee.2007.12.046

61.Jun YW, Seo JW and Cheon J. Nanoscaling Laws of Magnetic Nanoparticles and Their Applicabilities in Biomedical Sciences. Accounts of chemical research. 2008:41(2):179 -189.

62.Zhang HL, Lai GS, Han DY, Yu AM. An amperometric hydrogen peroxide biosensor based on immobilizationof horseradish peroxidase on an electrode modified with magnetic dextran microspheres. Anal Bioanal Chem. 2008;390:971-977. http://dx.doi.org/10.1007/ s00216-007-1748-3

63.Lai GS, Zhang HL, Han DY. A novel hydrogen peroxide biosensor based on hemoglobin immobilized on magnetic chitosan microspheres modified electrode. Sensors and Actuators B. 2008;129:497-503. http://dx.doi.org/10.1016/j.snb.2007.08.041

64.Mäkiranta J, Verho J, Lekkala J and Matintupa N. Novel measurement method for magnetic particles. Proceedings of the 28th Ieee Embs Annual International Conference.

65.Yang $H$, Chen L, Lei C, Zhang J, Li D, et al.Giant magnetoimpedance-based microchannel system for quick and parallel genotyping of human papilloma virus type 16/18. Appl.Phys.Lett. 2010;97:043702. http://dx.doi.org/10.1063/1.3467833

66.Chen L, Bao CC, Yang H, Li D, Lei C,et al. A prototype of giant magnetoimpedance-based biosensing system for targeted detection of gastric cancer cells. Biosensors and Bioelectronics. 2011;26(7):32463253. http://dx.doi.org/10.1016/j.bios.2010.12.034

67.Thévenot DR, Toth K, Durst RA and Wilson GS. Electrochemical biosensors: recommended definitions and classification. Biosensors and Bioelectronics. 2001;16(1-2):121-131

68.Sun W, Zhong JH, Qin P, Jiao K. Electrochemical biosensor for the detection of cauliflower mosaic virus $35 \mathrm{~S}$ gene sequences using lead sulfide nanoparticles as oligonucleotide labels. Analytical Biochemistry. 2008;377:115-119. http://dx.doi.org/ 10.1016/ j.ab.2008.03.027

69.Zhang W, Yang T, Huang DM, Jiao K. Electrochemical sensing of DNA immobilization and hybridization based on carbon nanotubes/nano zinc oxide/chitosan composite film. Chinese Chemical Letters. 2008;19:589-591. http://dx.doi.org/10.1016/j.cclet. 2008.03.012

70.Ferapontova EE, Olsen EM, Gothelf KV. An RNA Aptamer-Based Electrochemical Biosensor for Detection of Theophylline in Serum. AM.CHEM.SOC. 2008;130:4256-4258. http://dx.doi.org/10.1021/ ja711326b

71. Yang ML, Wang J,Li HQ,Zheng JQ,Wu NN. A lactate electrochemical biosensor with a titanate nanotubeas direct electron transfer promoter. Nanotechnology. 2008;19:075502. http:// doi: 10.1088/0957-4484/19/7/075502.

72. Chai R, Yuan R, Chai YQ, Ou CF, Cao SR, Xuelian Li. Amperometric immunosensors based on layer-by-layer assembly of gold nanoparticles and methylene blue on thiourea modified glassy carbon electrode for determination of human chorionic gonadotrophin. Talanta. 2008;74:1330-1336. http://dx.doi.org/ 10.1016/j.talanta.2007.08.046

73.Maeng JH, Lee BC, Ko YJ, Cho W, Ahn Y, Cho NG. A novel microfluidic biosensor based on an electrical detection system for alpha-fetoprotein. Biosensors and Bioelectronics. 2008;23:13191325. http://dx.doi.org/10.1016/j.bios.2007.11.019

74.Marchesini GR, Buijs, Haasnoot W, Hooijerink D, Jansson O, and Nielen MWF. Nanoscale affinity chip interface for coupling inhibition SPR immunosensor screening with Nano-LC TOF MS. Anal Chem. 2008;80:1159-1168. http://dx.doi.org/10.1021ac071564p

75.Lee HY, et al. Self-organized functional lipid vesicle array for sensitive immunoassay chip., Ultramicroscopy. 2008.

76.Chen SH, Yuan R, Chai YQ, Li N. A New Enzyme Immobilization Technique Based on Thionine-Bovine Serum Albumin Conjugate and Gold Colloidal Nanoparticles for Reagentless Amperometric Biosensor Applications. Electroanalysis. 2008;20(4):418 - 425.

77.Cao T, Wang AF, Liang XM, Tang HY, Auner GW, Salley SO Patterned Immobilization of Antibodies in Mechanically Induced Cracks. Phys.Chem.B. 2008;112:2727-2733. http://dx.doi. org/10.1021/jp711070k

78. Craig I, McLaughlin JA. SPR and AFM study of engineered biomolecule immobilisation techniques. Proceedings of the 28th IEEE EMBS Annual International Conference, New York City, USA, 2006.

79. Yuk JS, Jung JW, Kim YM and Ha KS. Analysis of protein arrays with a dual-function SPR biosensor composed of surface plasmon microscopy and SPR spectroscopy based on white light. Sensors and Actuators B:Chemical Volume . 2008;129(1):113-119. http://dx.doi. org/10.1016/j.snb.2007.07.089

80.Galopin E, Beaugeois M, Pinchemel B, Camart JC, Bouazaoui M, SPR VT. biosensing coupled to a digital microfluidic microstreaming system. Biosensors and Bioelectronics. 2007;23:746-750. http://dx.doi.org/10.1016/j.bios.2007.08.009

81.Shan XN, Foley KJ and Tao NJ. A label-free optical detection method for biosensors and microfluidics. Applied Physics Letters. 2008;92:133901.http://dx.doi.org/10.1063/1.2906486

82.Ansari SG, Ansari ZA, Wahab R, Kim YS, Khang G, Shin HS. Glucose sensor based on nano-baskets of tin oxide templated in porous alumina by plasma enhanced CVD.Biosensors and Bioelectronics. 2008;23:1838-1842. http://dx.doi.org/10.1016/ j.bios.2008.02.022

83. Lu BW, Chen WC. A disposable glucose biosensor based on dropcoating of screen-printed carbon electrodes with magnetic nanoparticles. Journal of Magnetism and Magnetic Materials. 2006;304: e400-e402. http://dx.doi.org/10.1016/j.jmmm.2006.01.222

84.Li G, Wen HX, Wang HY, Wu Y and Parajuli R. A pyrrole quinoline quinone glucose dehydrogenase biosensor based on screen-printed carbon paste electrodes modified by carbon nanotubes. Meas.Sci. Technol. 2008;19:065203.

85.Manesh KM, Kim HT, Santhosh P, Gopalan AI, Lee KP. A novel glucose biosensor based on immobilization of glucose oxidase into multiwall carbon nanotubes-polyelectrolyte-loaded electrospun nanofibrous membrane. Biosensors and Bioelectronics. 2008;23; 771-779. http://dx.doi.org/10.1016/j.bios.2007.08.016

86.Zou YJ, Xiang CL, Sun LX, Xu F. Glucose biosensor based on electrodeposition of platinum nanoparticles onto carbon nanotubes and immobilizing enzyme with chitosan- $\mathrm{SiO}_{2}$ sol-gel. Biosensors and Bioelectronics. 2008;23:1010-1016. http://dx.doi.org/10.1016/ j.bios.2007.10.009

87.Yu JJ, Yu DL, Zhao T, Zeng BZ. Development of amperometric glucose biosensor through immobilizing enzyme in a Pt nanoparticles/ mesoporous carbon matrix. Talanta. 2008;74:1586-1591. http://dx.doi.org/10.1016/j.talanta.2007.10.005

88.Liao KC, Thieo HE, Frances J R, Marcu L, William Clifton, Gerald EL. Percutaneous fiber-optic sensor for chronic glucose monitoring in vivo. Biosensors and Bioelectronics. 2008;23: 1458-1465. http://dx.doi.org/10.1016/j.bios.2008.01.012

89.Kusakari A, Izumi M, Ohnuki H. Preparation of an enzymatic glucose sensor based on hybrid organic-inorganic LangmuirBlodgett films: Adsorption of glucose oxidase into positively charged molecular layers. Colloids and Surfaces A: Physicochem. 2008;321 : 47-51. http://dx.doi.org/10.1016/j.colsurfa.2008.02.032 
90.Christopher JJ, Nikolay Z, Anthony EGC and Judit M Nagy. Proteomics, nanotechnology and molecular diagnostics.Proteomics. 2008; 8:715-730. http://dx.doi.org/10.1002/pmic.200700665

91.Shi H, Xia T, Nel AE, Yeh JI. Part II: coordinated biosensors-development of enhanced nanobiosensors for biological and medical applications. Nanomed. 2007;2(5):599-614. http://dx.doi.org/ 10.2217/17435889.2.5.599

92.Yue M, Stachowiak JC, Lin H, Datar R, Cote R and MajumdaA. Label-Free Protein Recognition Two-Dimensional Array Using Nanomechanical Sensors. Nano Letter. 2008;8(2).

93. Galandova J, Ziyatdinova G and Labuda J. Disposable Electrochemical Biosensor with Multiwalled Carbon NanotubesChitosan Composite Layer for the Detection of Deep DNA Damage. Analytical Sciences. 2008;24.

94.Ghanbari KH, Bathaie SZ, Mousavi MF. Electrochemically fabricated polypyrrole nanofiber-modified electrode as a new electrochemical DNA biosensor. Biosensors and Bioelectronics. 2008.

95.McKenzie F, Faulds K, Graham D. Sequence-specific DNA detection using high-affinity LNA-functionalized gold nanoparticles. Small. 2007;3(11)1866-1868. http://dx.doi.org/10.1002/ smll.200700225

96.Ma Y, Jiao K, Yang T, Sun DX. Sensitive PAT gene sequence detection by nano-SiO2/p-aminothiophenol self-assembled films DNA electrochemical biosensor based on impedance measurement. Sensors and Actuators B. 2008;131:565-571. http://dx.doi. org/10.1016/j.snb.2007.12.046

97.Zhang W, Yang T, Huang DM, Jiao K. Electrochemical sensing of DNA immobilization and hybridization based on carbon nanotubes/ nano zinc oxide/chitosan composite film. Chinese Chemical Letters. 2008;19:589-591. http://dx.doi.org/10.1016/j.cclet.2008.03.012

98. Vamvakaki V, Chaniotakis NA. Pesticide detection with a liposome-based nano-biosensor. Biosensors and Bioelectronics. 2007;22:2848-2853. http://dx.doi.org/10.1016/j.bios.2006.11.024

99. Substrate-bound tyrosinase electrode using gold nanoparticles http://nanobe.org

anchored to pyrroloquinoline quinone for a pesticide biosensor. Sensors and Actuators B. 2008;133;1-4. http://dx.doi.org/10.1016/ j.snb.2008.01.055

100.Moldovan C, Iosub R, Radu C, Necula D, Ion M. Biosensor for pesticides detection in food.

101.Qiao YB, Jian FF, Bai Q. Bioconjugation of zirconium uridine monophosphate: lication to myoglobin direct electrochemistry. Biosensors and Bioelectronics. 2008;23:1244-1249. http://dx.doi. org/10.1016/j.bios.2007.11.008

102.Zhu HY, White IM, Suter JD, Zourob M, Xudong Fan. Opto-fluidic micro-ring resonator for sensitivelabel-free viral detection. Analyst. 2008;133: 356-360. http://dx.doi.org/10.1039/b716834a

103.Medley CD, Smith JE, Tang ZW, Wu YR, Bamrungsap S and Weihong Tan. Gold Nanoparticle-Based Colorimetric Assay for the Direct Detection of Cancerous Cells. Anal.Chem. 2008; 80: 1067 1072. http://dx.doi.org/10.1021/ac702037y

104.Prow TW, Bhutto I, Grebe R, Uno K, Merges C, Mcleod DS, Lutty GA. Nanoparticle-delivered biosensor for reactive oxygen species in diabetes. Vision Research. 2008;48: 478-485. http://dx.doi. org/10.1016/j.visres.2007.09.019

105.Li BL, Du Y, Wei H, Dong SJ. Reusable.label-free electrochemical aptasensor for sensitive detection of small molecules. Chem.Commun. 2007;3780-378228. http://dx.doi.org/ 10.1039/b707057h

106.Lee MR and Fauchet PM. Nanoscale microcavity sensor for single particle detection. Optics Letters. 2007;32(22). http://dx.doi.org/ 10.1364/OL.32.003284

Copyright:(c) 2011 C. Gui, et al. This is an open-access article distributed under the terms of the Creative Commons Attribution License, which permits unrestricted use, distribution, and reproduction in any medium, provided the original author and source are credited. 